\title{
TEMPORAL INFERENCES IN CONVERSATION
}

\section{Christine PaUl}

Free University, Berlin, Germany

christinepaul2002@yahoo.de

\begin{abstract}
Within this article, I explore how coproductions (expansions made by a second speaker upon a previous utterance) and questions regarding prior utterances work to verbalize inferences regarding the temporal information in spoken German conversation. While questions regarding prior utterances and coproductions are traditionally understood to have different communicative functions (signaling understanding/ misunderstanding; turn taking) to coproductions, empirical data shows how these expression types enable the speaker to gradually verbalize different strengths of assumption about details of the previous turn. These two expression types are not a dichotomy, but a continuum.
\end{abstract}

\section{Introduction}

In conversation, coproductions (expansions upon a previous utterance, made by a second speaker) are able to verbalize what a prior speaker implied or was about to say.

(1)

a: $\quad$ [...] ich hab nochmal drei jahre geographie studiert;

$i$ : jetzt nach der wende,

a: $\quad$ jétzt nach der wende ja. neunzig bis dreiundneunzig.

a: $\quad[\ldots]$ I went back to the university and studied geography for 3 years;

i: $\quad$ now after the [Berlin] wall has fallen,

a: $\quad$ now after the wall has fallen. 90 till 93 (B100 ON, 210)

Even though this phenomenon has been given different names (e.g. "colaborative utterances" Sacks: 1992; "affiliating utterances" Lerner: 2004; "collaborative productions" Szczepek: 2000; "collaborative turn sequences" Bolden: 2003), research commonly tends to emphasizes that coproductions are cooperative acts, using common knowledge and developing the syntactic structure of the prior turn in order to complete actions, show understanding, make comments or, in a competitive way, in order to get the turn (Lerner: 2004; Hayashi:2004; Helasvuo: 2004; Szczepek, Beatrice: 2000). While the action level and the syntactic and prosodic structure has received wide attention, the lexical level, e.g. exactly which kind of data is expanded upon, has so far received little attention .

While hearers who perform coproductions seem to verbalize what the prior speaker implied or was about to say, questions asked regarding prior utterances seem to have the opposite function, since they are commonly defined as demonstrating some kind of 
misunderstanding or a lack of knowledge ${ }^{1}$. Consequently, prior research has understood the two practices as expressing opposite purposes. As Lerner states in regard to preemptive completions:

"Pre-emptive completions are ordinarily produced as a rendition of "what the other was going to say' but are not composed as a guess (e.g. with a try-marker) that would explicitly inviting acceptance or rejection. However, pre-emptive completions are taken by the original speaker of the TCU they complete as candidate completions (implementing an action) that can be accepted or rejected." (Lerner: 2004:229)

Empirical data show that both communicative practices, that is coproductions and questions regarding prior utterances, enable a speaker to verbalize inferences about prior utterances. The purpose of this paper is to show the explicit aspect of the inference processes: distinct communicative devices serve to verbalize varying strengths of assumption about inferences. While it is commonly known that questions elicit information, in my data it is shown furthermore that not just questions but all temporal coproductions get a response, which can be explained by prosodic and turn taking rules on one hand, and by the interactiv need for a confirmation on the other. That both questions and coproductions get a feedback from the prior speaker, corresponds to the Relevance - theoretic claim that hypothesis formation and confirmation are at the basis of comprehension processes.

I have restricted my analysis to temporal inferences, since metaphysically, every proposition is realized in time (Recanati:2007), and in German, temporal reference is almost obligatorily verbalized through the tense morpheme of the finite verb. Thus, it is very likely that inference processes regarding the temporal reference occur. Furthermore, temporal inferences have not yet been analysed and the fact that temporalilty is at least to a certain extend measurable gives certain advantages for the empirical analysis of temporal inference, in comparison to other more vague semantic concepts.

In order to analyse temporal inferences in conversation, I will firstly show how temporal reference is established in German. Secondly, I will give a short overview of previous research into inferences. Then, in the most important part, the empirical data will

\footnotetext{
${ }^{1}$ There is a long research tradition regarding questions, which are commonly defined either as a special type of sentence or as speech acts. While the 'interrogative sentence' is characterized by the occurrence of interrogative pronouns, word order, intonation, question mark and others, the speech act, e.g. the act of asking a question, is defined as a request to provide certain information. Groenendijk \& Stokhof (1997:1057) argue for a third use of the concept 'question' "the one in which it refers to the 'thing' which is being asked, and which, in consequence, may be (partially) answered. This object can be viewed as the semantic content, or sense, of an interrogative." My approach to the relation of coproductions and questions goes within the lines of this third use of the concept 'question'.

Questions regarding prior utterances are a subcategory of questions. For a discussion of the various research, compare Rost-Roth (2006), who defines questions regarding prior utterances: „Ausdruck eines Nicht-Wissens bzw. Informationsdefizits in Bezug auf vorausgehende Äußerungen des Gesprächspartners“" (M. Rost-Roth, 2006: 43). I restrict my analysis to questions about prior utterances, but notice that for example Noh, Eun-Ju (1995) argues that echoquestions can refer to a non linguistic content, just as images or signals. This type of question regarding non-linguistic context is not an object of this research paper.
} 
demonstrate how coproductions and questions regarding prior utterances verbalize temporal inferences about temporal information with varying strengths of assumption.

\section{Temporal Reference in Conversation}

How temporal information is provided in discourse is a widely discussed research topic. There are different kinds of sources which provide temporal information (Recanati:2007):

- Every proposition is realized locally and temporally, independently of the restrictions of each language. ${ }^{2}$

- Syntagmatically, temporal information is provided by the logical form of the tense morpheme.

- $\quad$ Pragmatically, temporal information can be introduced additionally by free enrichment and contextually provided information.

- Lexically,

- verbs differ in the lexic structure, thus some verbs imply a temporal argument while others do not (compare for example, telic and atelic verbs, such as dance and take [a long/ some] time).

- The lexical content of the verb provides additional temporal information, such as Aktionsart (static vs dynamic, durative vs. non-durative, punctual vs. iterative, etc.)

The diverse linguistic devices which provide temporal information enable the speaker to specify the moment in time very concretely (1) or to provide the temporal information merely by the tense - morpheme (2).

(2)

(a) s: !um neunzehn uhr ich war um néunzehnuhrzehn! in der sonnenallee; es war ein donnerstag abend; (B112WN, 24)

s: $\quad$ !at 7 p.m. I was at 7 and 10 ! at the street sonnenallee; it was thursday evening

(b) "I will go to China"

Example (2b) shows that without any further specification, the tense-morpheme can refer to a concrete or unconcrete moment in time. The hearer has to infer if the speaker has a special date in mind when he or she will go to China or whether he or she makes a claim

${ }^{2}$ Recanati focuses on European languages, but languages differ in the realisation of temporal information by the finite verb. Smith (2007) differentiates between 3 languages-types, depending upon whether tense morphemes are obligatory or facultatively verbalized. Fully tensed languages (such as English or German), verbalize tense morphemes obligatorily in main clauses through the finite verb. Mixed temporal languages (such as Navajo and other Athabaskan languages) give direct temporal information by inflectional morphemes and/or temporal particles and clitics, but they are syntactically optional. Tenseless languages, such as Mandarin Chinese and Thai and some Mayan languages do not have temporal inflections or particles. According to Smith, this distinction does not refer to temporal adverbs, which are optionally available in all languages. 
for some non-specific day in the future. ${ }^{3}$ Thus, the degree of explicitness regarding temporal information can differ, depending upon the additional information provided to the tense morpheme, for example temporal adverbs, information provided contextually, discourse principles and world knowledge, all of which allow the hearer to infer when the event or the situation takes place. But even in examples such as (2 a), where the location on the time line is very precise, the bounds of the time spans are not explicitly specified and have to be inferred.

But which information does the tense-morpheme convey? Since Reichenbach (1947), the temporal reference is most commonly explained by three time spans and two temporal relations: The Speech Time (for spoken language), that is the moment of utterance, is the deictic reference point in discourse. There are two other time spans or points that relate to the Speech Time. On one hand there is the Situation Time (Smith:2007; Klein: 2009; 1994 or Event time, Reichenbach: 1947): the time in which an event or state occurs, and the Reference Time (Smith:2007; or Topic Time, Klein:2009; 1994), the perspective from which the situation is presented or the time span about which a claim is made. ${ }^{4}$ The Speech Time is related directly to the Reference Time, and the Reference Time to the Situation Time, whereby the relation can mean after, before, simultaneously or overlapping with each other. If this analysis is correct, there is only an indirect relation between the Speech time and the Event or Situation Time, which one is more precisely indicated in language which mark explicitly aspect. ${ }^{5}$

(3) Suzanne left.

(Reference Time $<$ Speech Time; Reference Time $=$ Situation Time)

(4) Leigh would arrive in three days.

(Reference Time < Speech Time; Reference Time < Situation Time)

(Examples from Smith: 2007)

${ }^{3}$ Compare Recanati (2007:139) for this example, and his reference to (1973) "I didn't turn off the stove." (arguing for an anaphoric use) or "Tolstoy wrote War \& Peace" (Smith, 2007: 424) describing a deontic use.

${ }^{4}$ Tense forms such as past perfect (had ended) or future perfect (will have spent) show the need for an additional reference point or intervall as the Reference time.

${ }^{5}$ Generally, it can not be the Situation Time that refers to the tense morpheme, which illustrates Klein (1994:4, numeration according to Klein) with the following example:

(3) «What did you notice when you looked into the room?

(4) There was a book on the table. It was in Russian.»

The situation in (4) can be described by the proposition with the verb in infinitive is 'book being on the table' and 'book being in Russian'. But, since the book stays in Russian and we do not know how long the book was on the table, it is not the Situation Time which is indicated by the tense morpheme of the finite verb and which is related to the Spech Time. There is another time span; the Topic Time (or Reference Time, Reichenbach, Smith), that is in (4) the moment when the speaker enters the room, which is before (or after or simultaneous) to the Speech Time. Languages which express aspect can indicate this relation more specifically. 
This demonstrates that even if one time span or bound is explicitly specified, there are several other temporal aspects which remain undetermined; they are either of no further interest or are to be inferred.

\section{Inferences and projections}

Part of the cooperative act of meaning construction are inferring processes. Inferences are cognitive processes, which deduce or add something to the explicit semantic content in order to get the implicit meaning. ${ }^{6}$ They are largely discussed within theoretical frameworks, based on the Gricean definition of what is said vs. what is implicated, redefining and focusing upon either the communicative principle (most famously by Horn 2007, Levinson 2000, Sperber\&Wilson 1996), on further inference processes at the explicit level, or on the question as to what extent the processes are linguistically (Stanley 2007) or contextually driven (Carston 2002, Recananti 2004). While communication is clearly stated as a cooperative act ${ }^{7}$, inference processes are mainly analyzed as personal processes of the hearer, which occur in order to evaluate the speaker's intention. Empirical research shows that readers can anticipate words within reading tasks (Van Berkum: 2008), and that within conversation, some linguistic devices such as discourse markers or modal particles (in German) can be analysed regarding their inferential potential (Fraser: 1999; Dietrich:1999). Furthermore, projections are analysed, in order to explain turn-taking, as anticipating devices for upcoming grammatical structures and actions, and based on the syntactic, the prosodic or the interactive structure (Auer: 2010; 2002; Barth-Weingarten: 2009; Hayashi:2004). Thus, while inferences are discussed on a lexical level with reference to the 'what was said' vs 'what was meant' distinction, projections are analyzed in order to explain what comes next in conversation. It is not initially clear, wether coproductions are based mainly on projections or inferences or both. The difference between inferences and projections is on the one hand based upon the level of analysis- that is the action level; or syntactic and prosodic cues vs. lexical cues- and on the other hand upon the level of temporality in comprehension. While projections are anticipatory and forward-thinking or simultaneous, inferences are processed retrospectively or simultaneously to the produced utterance. This is a difference in the production process: projections hint at a possible upcoming structure, which will not necessarily be fulfilled, and on the hearer's side, they help to anticipate and plan the upcoming discourse. They give an idea beforehand, which influences the communication and understanding process. While projections are a prestructuring device, inferences, on the other hand, are post-structuring devices. They allow the production of additional information to specify what has already been said and to add further details. Projections and inferences are both parts of the understanding

\footnotetext{
${ }^{6}$ The distinction between implicit and explicit meaning seems to be a theoretic simplification and cannot be drawn independently of a theoretic framework. Compare Linke \& Nussbaumer (2000) for an overview of different concepts of implicit meaning, for example as part of the conventional meaning, such as presuppositions and entailments or as dependent on the use, such as pragmatic presuppositions, cognitive approaches and the Relevance-theoretic framework.

${ }^{7}$ That communication is a cooperative act has been stated most famously by Grice (1989), Clark (1996) and more recently by Tomasello (2009).
} 
process, working on different communicative levels and at different moments of the understanding process. The analysis of both devices together would seem to be complementary. The question remains as to whether the theoretical approaches of hypothesis formation and confirmation are supported by empirical data.

\section{Empirical Analysis}

My analysis is based upon two different corpora. One corpus is rather formal and contains 42 counselling interviews (consultations) of different fields, e.g. course guidance, legal advice, social counselling and homeless counselling. These are asymmetrical conversations of varying length, often within an institutional setting, where speakers belong to different social classes and come from different places in Germany. The other corpus contains 60 narrative interviews and 28 hours of spoken German. Inhabitants of East and West Berlin are talking about how they experienced the fall of the Wall in November 1989 and how they are living in the united Berlin at the moment of the interview, that is, 4 years later. Often the conversations are rather informal, as some of the interviewers and interviewees are friends or acquaintances.

The data has been analyzed both quantitatively and qualitatively. All temporal coproductions and questions about prior utterances were counted and analyzed based on the following questions:

1. The reference point of temporal inferences: What do coproductions and questions about prior utterances focus upon?

2. Inference formation: How is the strength of assumption verbalized?

3. Inference confirmation: Do coproductions receive a feedback similar to answers?

\subsection{The focus of temporal inferences}

Both corpora together contain 182 coproductions and questions which refer to temporal aspects of prior utterances. There is a clear quantitative difference in focus: While only 1 percent ( 2 tokens) refer to the frequency, and only 15 percent ( 28 tokens) to the duration, 84 percent (152 tokens) focus on the temporal location on the timeline. ${ }^{9}$

This seems to support the hypothesis that temporal information regarding the precise moment in time tends to be underspecified in discourse, and is possibly more difficult to infer or more relevant than other temporal aspects such as frequency or duration. Since quantitatively, questions and coproductions concerning the frequency and duration play only a minor role in my data, I concentrate in what follows on questions and

\footnotetext{
${ }^{8}$ More information about both corpora are available at http://userpage.fu-berlin.de/ nordit/HP/ and at http://dsav-oeff.ids-mannheim.de/DSAv/KORPORA/BG/BG_DOKU.HTM.

${ }^{9}$ It is important to notice that within conversations about historical events, as is the case in the 'Berliner Wendekorpus', temporal questions such as 'what happened before/afterwards' play an important role. The quantitative data shows this clearly, since 114 questions and coproductions could be found in the corpus of fall of the Wall, and only 68 in the corpus of counselling interviews.
} 
coproductions regarding the temporal location on the time line, which I call the temporal operator.

\subsection{Inference formation}

I start out from the relevance-theoretical concept of 'representation by resemblance', developed by Blakemore (1994) in her analysis of Echo questions: "The suggestion here is that by echoing A's utterance, an echo questioner is communicating the proposition that his utterance is being used as a representation of A's utterance." (Blakemore, 1994: 205) According to Blakemore, the representation can be realized at different linguisitic levels. I claim that all kinds of coproductions and questions regarding prior utterances can represent the temporal operator of prior utterances. Both devices can be used in order to restrict one of the time spans or bounds of the prior utterances and localize it more precisely on the time line. In order to pinpoint the temporal operator, hearers can suggest their inferences gradually according to the question or coproduction type used respectively. In order to illustrate this thesis, I will provide an example of each questionand coproduction type and analyze the inferential potential in it and the strength of assumption verbalized. With the different linguistic devices, a speaker verbalizes gradual strengths of assumption, starting with wh-questions, which do not express any hypothesis at all, yes-no-questions, which serve to verbalize an hypothesis with uncertainty, and coproductions, which reveal the temporal operator with certainty.

With wh-questions, hearers can request prior speakers to put in more concrete terms the temporal information, verbalizing the concrete temporal category with a variable, as you can see in the following example:

(5)

Eb11 november ${ }^{\wedge}+$ vier jahre ist es jetzt her daß die grenzen geöffnet [...]? wann und wie habt ihr von der grenzöffnung gehört^ und was habt ihr daraufhin unternommen_?

ASSI naja das war $s^{\wedge} d a \beta$ wir/ich lag schon im bett und hab geschlafen_und mein mann hat michh ge'weckt [...] und da ham-ma uns dit anjekuckt im fernsehn_ und konnten dit allet jar nich so recht fassen daß die grenzen wirklich offen sind_ $+1+$ sso ham wir dit erfahrn_=

USSI =? wie spät war dit da^? $(B 110,5)$

Eb11 november ${ }^{\wedge}+$ four years ago they opened the borders $[\ldots]$ ¿When and how did you hear of the opening of the borders ${ }^{\wedge}$ and what did you do afterwards_?

ASSI well $\wedge^{\wedge}$ we/ I was sleeping already in bed _ and my husband woke me up $[\ldots]+$ and there we watched it in TV_ we couldn't believe that the borders where indeed open_+1+ so we found it out=

USSI $\quad=$ What time was it ${ }^{\wedge}$ ?

In this example, the time span is established by the following steps:

The first speaker's question already provides a temporal frame, using the calendaric category "november"; the deictic category "four years ago" and the historical date of "opening of the borders" which leads to the temporal operator the 9th of November and 
the day after. Furthermore, from the lexical information 'sleeping' the hearer can infer that the described situation is in the late evening or night of the 9th. The wh-question (What time was $i t^{\wedge}$ ?) restricts this information to an even more precise and objective category, that is, the hour. The hearer Ussi doesn't suggest any potential temporal operator- she asks for a specification. ${ }^{10}$ Naturally, this question can be explained not only by an interest in the exact moment in time, but also because of the communicative goals of all questions types regarding prior utterances, such as maintenance of the conversation, extending the topic, giving back the turn and winning time. Even though these communicative functions can be of central interest, even more crucial in narrative interviews, is whether the question type provides a different level of an inferential process. While wh-questions only invite the speaker to verbalize the questioned temporal information without any suggestions, alternative-questions supply two possible temporal operators:

(6)

Sw06 ja und so kontakte $+1+$ die fingen denn an als ich denn ver/ eh im krankenhaus im hubertus krankenhaus in nikolassee (h) angefangen hab zu arbeitn und als ich denn mein abitur nachholte auf-m berlin kolleg in schöneberg also da bekam ich denn ehm kontakte

Si I war das vor neununachtzich dann odal oda\&nach neununachtzich\&

Sw06 \&das war vor neunun \&achtzich \&ja \& (B111NW, 277)

Sw06 yes and the contacts $+1+$ they begunn then when I started working eh / at the hospital at the hospital hubertus near by the lake Nicolas (h) and then when I made up for my high school diploma (Abiur) at the college in Berlin Schöneberg well, there I made ehm contacts

\section{Si I (h) that was before or/ or \&after $89 \&$}

Sw06 \& that was before $89 \&$ yes \&

With the alternative-question the hearer offers two possible temporal operators: before 89 and after 89 . Nevertheless, the alternative-question covers the same temporal scope as the wh-question 'when?', but in providing two possible time spans, alternative-questions already demonstrate an inferential activity, even though it is with much less certainty. The bound year 89 is selected because of the relevance of the historical events, which changes the social context and so the interpretation of what was said. Naturally, these time spans could be more concrete, and thus show a higher degree of inferential activity, for example: Did it happen in 88 or 90 ? Thus the difference between a wh-question and an alternative-question does not consist in the concreteness of the provided time spans or the scope of the temporal operator, but on the hypothesis verbalized regarding the temporal information; that means the difference consists in the inferential activity.

\footnotetext{
${ }^{10}$ Temporal wh-question can have a further function, in that they can verbalize a doubt regarding the truth-conditions of the prior utterance or ask for the grade of certainty about a statement: A: $I$ will speak to her about it. B: When? With the wh-question, the speaker is able to express certain doubt regarding the previous statement, because in pinpointing the temporal operator, the statement loses the non-commitment. However, I have not found any empirical examples in my data to support this idea.
} 
Logically, presenting only one hypothesis shows more certainty about a temporal operator then presenting two, as is the case with yes-no questions:

(7)

Si I hast denn irgenwie auch gleich ossis kennenjelernt ${ }^{\wedge}$ mit denen du dann ne weile kontakt ${ }^{\wedge}$ hattest ${ }^{\wedge}$ oder eigntlich gar nich ${ }^{\wedge}$

Sw13 [...] wir warn auf seminarfahrt ja ja hinter berlin in so $m$ dorf $+[\ldots]$ das war irgenwie so $n$ stasiheim davor oder so + das war eigntlich ganz gut $+x x$

Si I wart ihr da gleich im sommer danach

Swl3 wir warn $\mathrm{hm}+$ ich glaub das war/ + ich weiß gar nich $[\ldots](\mathrm{B} 61 \mathrm{~W}, 48)$

Si I did you met people from the east shortly after ${ }^{\wedge}$ with whom you stayed in contact $^{\wedge}$ for a while ${ }^{\wedge}$ or not really ${ }^{\wedge}$

Sw13 $\quad[\ldots]$ we traveled to a village there nearby Berlin $+[\ldots]$ that was a house of the state security or something similar before + that was not bad $+\mathrm{xx}$

$\mathrm{Si}$ I were you there the following summer

Sw13 we were there hm + I think it was / +I'm not sure $[\ldots]$

Here we have the same pattern: On the one hand there is a time span already established, signalled by the tense form 'present perfect' which indicates that the reference time is before the speech time. On the other hand, within the discourse, "shortly after" refers to shortly after 89. Furthermore, in Germany people are more likely to travel in the Summer than in Winter. Altogether, this information allows the hearer to infer the temporal operator "the following summer", i.e the temporal operator of the yes-no question which makes concrete the previously established temporal operator and thus shows an inferential activity.

In the same way as yes- no questions, coproductions can pinpoint the temporal operator of prior utterances:

(8)

a: [...] ich hab nochmal drei jahre geographie studiert;

$i$ : jetzt nach der wende,

a: jétzt nach der wende ja. neunzig bis dreiundneunzig. (B100 ON, 210)

a: $\quad[\ldots]$ I went back to the university and studied geography for 3 years;

i: now after the [Berlin] wall has fallen

a: now after the wall has fallen. 90 till 93

The coproduction reduces the prior time span- indicated through tense, 'before the Speech Time'- in verbalizing the left border at the time line: "now after the wall has fallen". Since political and social reality changed completely after 89 , the hearer assures not only the right localisation on the time line, but also the right interpretation of what was said - studying geography in one political system or the other. The restrictive function and the temporal scope of coproductions conform to those observed in questions about prior utterances. But, if a hearer connects a temporal operator in a syntactically coherent form with the prior utterance, the temporal operator is presented as a possible part of the prior utterance and, because of the intonation and syntax, 
features as a strong assumption. Furthermore, interactively, speakers adopt a positive attitude and demonstrate care with coproductions.

While Lerner states that affiliated utterances have no question markers, I disagree. "Appendor questions", defined as "prepositional phrases which have question intonation on them" (Sacks, 1992:660) are clearly related to coproductions, since they are syntactically coherent with the structure of the previous utterance:

(9)

LEO $\quad$ [...] ich arbeite ja nun als freiberuflicher $+\backslash$
EbO9 $\quad$ ?jetzt nach der wende?
LEO
ja beleuchtungsmeister $(B 09 O$, Z. 221)

LEO $\quad[\ldots]$ well, now I work as a freelancer +1

Eb09 ?now after the wall has fallen?

LEO yes, as a lighting technician

The hearer's contribution can be analyzed either as an elliptic yes-no question or as a coproduction with interrogative prosodic features. The distinction seems to be terminological and not empirically based, since there is no clearcut empirical distinction between an elliptic question of this coherent syntactic form and an appendor question. In my opinion, the prosodic feature shows a stronger request to obtain an answer and so the difference consists in the strength of assumption.

In conclusion, while coproductions and questions regarding prior utterances can restrict the verbalized temporal operator, both devices can be analyzed regarding their increasing strength of assumption: starting with wh-questions, which do not verbalize any inference at all, alternative-questions, which express two hypothesis with a high level of uncertainty, yes-no questions and coproductions with interrogative features, which present the inferred temporal operator with a intermediate level of uncertainty and coproductions, which present the temporal operator as certain.

This scale of varying strength of assumption corresponds to (epistemic) modality. It is commonly known that the basic concept of modality is validity, whereby the central categories are epistemic and deontic modality. ${ }^{11}$ As described by Dittmar and Terborg (1991:356), epistemic modality,

[...] refers to the probability which a speaker grants or the 'truth' of the content of an utterance (the proposition). 'True' is not to be understood in the logical sense, but rather as the evaluation of the speaker.

* probably p true/ given

+ probably p true/ given

$\circ$ probably $\mathrm{p}$ true/ given

/ probably p true/ given

- probably p true/ given

'*' marks the area in which the speaker thinks $p$ is true

'+' marks an area near '*' but which is not identical with it

${ }^{11}$ Dittmar and Terborg (1999:259f) distinguish five different categories of modality: epistemic modality, deontic modality, ability and deontic possibiliy, volition and deontic necessity, and, as a category derived from epistemic modality, "epistemic means which do not correspond to the speaker's evaluation at the time of speech (other's evaluation)". 
'o, marks a middle area

'/ marks an area near 'not true/ given but is not identical with it

'-' marks the area in which the speaker thinks $p$ is false.

These graduated areas resemble the different strengths of assumption verbalized by coproductions ("*"), coproductions with a question mark ("+") and yes-no- questions ("“"). Since wh-questions don't formulate a full proposition, they are not represented in this scale.

The quantitative data supports the qualitative analysis, that wh-questions, yes-noquestions and coproductions are the prototypes employed in order to verbalize the temporal operator. Interestingly, the quantity of wh-questions $(21 \%)$, yes-no questions $(22 \%)$ and coproductions $(22 \%)$ of the temporal operator is very similar. Other comments of the hearer regarding the temporal operator are less frequent. The next groups are repetitions and echo questions (10\%), alternative-questions (9\%), declarative questions (7\%) and coproductions with a question mark $(6 \%)$; the rest are mixed types. Thus, it seems that both the qualitative and the quantitative data support the hypothesis that different questions types and coproductions serve to express gradually an inferential potential regarding the temporal operator.

\subsection{Inference confirmation and sequential organisation}

As hypothesis formation is part of the inference process, so is hypothesis confirmation. Obviously, hypothesis confirmation is requested in the cases of questions about prior utterances and coproductions with interrogative features, such as an interrogative intonation. This is because questions, by definition, request an answer of the questioned content. (10)

The wish for feedback is not only prosodically indicated, but also lexically:

STUD: $\quad[\ldots]$ und da ham wa na@türlich befürchtet daß die uns besuchen \&kommen@@2@\&\&(xx)\&

Eb57: $\quad$ \&@(h)@@1@\& \&so gleich\& in den ersten tagen \&ja\&

STUD:

$\&$ ja\& ja gleich in den ersten tagen aber die kamen

nich $[\ldots](\mathrm{B} 57 \mathrm{~W}, 80)$

STUD: $\quad[\ldots]$ and, naturally, we were afraid they would visit us@

@2@\&\&(xx) \&

Eb57:

\&@(h)@@1@\& \& right\& in these first days \& really\&

STUD:

$\& y e s \&$ yes right in these first days, but they

didn't come $[\ldots](\mathrm{B} 57 \mathrm{~W}, 80)$

The responsive particle " $j a$ " can have a structuring function, signaling the end or the beginning of an utterance. Furthermore, if this particle " $j a$ " is uttered with a rising intonation, the particle has the function of asking for a feedback, as is the case in example (). 
Coproductions receive a feedback without any lexical or prosodic markers, even if the coproductions are voiced with a falling intonation structure:

67 BR: $\quad[\ldots] \quad * \ddot{a} h * \rightarrow$ mich würde nur mal

68 BR: interessieren $\leftarrow$ wo sind sie denn $\uparrow$ zwischenzeitlich

69 BR: gewesen von seit oktober |jetzt $\downarrow \mid$

70 RS: $\mid$ da $\mid$ war ich jetzt äh

71 BR: die ganze zeit über $\downarrow$

72 RS: in * $\rightarrow$ magdalehn $\leftarrow$ die ganze zeit

73 BR:

$74 R S: j o \downarrow * 3 *[\ldots](\mathrm{CK}, 1406.06)$

67 BR:

$[\ldots] *$ äh $* \rightarrow$ I would like to know where have you

68 BR: been $\uparrow$ in the meantime

69 BR: since october |now $\downarrow \mid$

70 RS: |well | I've been recently äh

$71 \mathrm{BR}$ : the whole time $\downarrow$

$72 \mathrm{RS}:$ in $* \rightarrow$ magdalehn $\leftarrow$ the whole time

73 BR:

74 RS: yes $\downarrow * 3 *[\ldots]$

Similar to declarative questions, the need for a feedback is as high as with any other question type. Even though with coproductions, the answer is not elicited, as in the case of questions, all temporal coproductions do receive a feedback. This can be explained by turn taking rules, since the temporal coproduction completes the intonation unit with falling intonation and a pause, thus indicating that an other speaker can take the turn. Nevertheless, in my data, the feedback of temporal coproductions always concerns the content, even if they are verbalized without any interrogative characteristics or in cases of redundancy:

c: dás konnt ich mir vorstellen aber nich was das/ dann kam und daß dieses system só so zusammenbrechen würde. so plötzlich.

i: so von einem tag \&auf den andern\&

c: \&so von einem \&tag auf den anderen. (B114,54)

c: thís I could imagine but not that / what happened afterwards and that this whole system would só so collapse. so suddenly.

i: so from one day \&to the next\&

c: \&so von einem \&tag auf den anderen.

The coproduction "so from one day to the next" is an reformulation of "so suddenly". There is no logical need to approve a coproduction which is based on a reformulation, 
since their semantic content is equal. ${ }^{12}$ Nevertheless, the coproduction is repeated by the first speaker in order to confirm it.

Coproductions are not only confirmed, sometimes the content is corrected or negotiated:

(13)

285 BR: $\quad$ fahren sie eigentlich mit nach

286 RS: nein leider net schad * ich muß

287 BR: seelangen ne:

288 RS: arbeiten gehn $*$ in die b a $f$ sechs

289 BR: die ganze zeit-

290 RS: wochen $\downarrow$ (...) * des überschneidet sich-

291 BR: $\rightarrow$ na ja gott

292 RS: ne

293 BR: dann ham=se natürlich wenn sie nich des geld ham $\leftarrow(\mathrm{CK}, 1400.43)$

285 BR: actually, do you go with us to

286 RS: no unfortunately not it's a pity * I have to

287 BR: seelangen no:

288 RS: work * at the b a s $\mathrm{f}$

$\operatorname{six}$

289 BR: the whole time-

290 RS: weeks $\downarrow$ (...)* it overlaps-

291 BR: $\rightarrow$ well jesus

292 RS: yeah

293 BR: then you have of course if you don't have the money $\downarrow \leftarrow$

The first part of the coproduction, the utterance "I have to work * at the b a sf" serves as explication as to why the student is unable to attend/ join the student's stay in "Seelangen". The temporal phrase "all the time", mentioned by the first speaker as part of the utterance, would have served as a complete explication, but mentioned by a second speaker, "all the time" scrutinizes the duration, in order to find out if there is still any possibility to join the student trip. With the coproduction, the professor shows interest in the reasoning of the student in asking for the temporal restriction and possibilities of joining the trip. The time span is slightly corrected by the first speaker, since both time spans merely overlap, as she explains. Thus, the temporal operator 'all the time' was not an implicit part of 'what was said/ meant'. This shows a difference in the backround of both speakers: while for the student the mere fact to have to work is reason enough for not joining the trip, its only after further explication good enough reason for the professor.

That all temporal coproductions are responded to or confirmed, is a further argument that coproductions and questions serve to verbalize and confirm temporal inferences. While the typical interrogative features request an answer, in the case of coproductions,

12 Regarding reformulations, compare: Kotschi, Thomas; Gülich, Elisabeth (1996) "Textherstellungsverfahren in mündlicher Kommunikation. Ein Beitrag am Beispiel des Französischen", in: Wolfgang Motsch (Hg.), Ebenen der Textstruktur. Sprachliche und kommunkiative Prinzipen, Tübingen (Niemeyer), 37-80. 
the syntactic coherence makes the speaker confirm the inferential suggestion of the hearer.

As such, coproductions are functionally, structured in the same way as questions about prior utterances:

\begin{tabular}{|c|c|c|c|}
\hline Speaker A & initial utteranc & & \\
\hline Speaker B: & $\begin{array}{l}\text { wh-question } \\
\text { about temporal } \\
\text { operator } \\
\text { - } \quad \text { explicit means } \\
\text { - } \quad \text { elicitation }\end{array}$ & $\begin{array}{l}\text { Yes-no question: } \\
\text { hypothesis about } \\
\text { temporal operator } \\
\text { - elicitation }\end{array}$ & 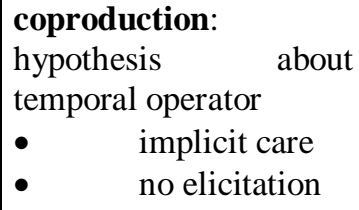 \\
\hline $\begin{array}{l}\text { Speaker A: } \\
\text { feedback }\end{array}$ & $\begin{array}{l}\text { Completion } \\
\text { temporal operator }\end{array}$ & \multicolumn{2}{|c|}{$\begin{array}{l}\text { Confirmation or correction of the temporal } \\
\text { operator }\end{array}$} \\
\hline
\end{tabular}

Table 1

The similar sequential organisation of coproductions and questions about prior utterances corresponds to the Relevance-theoretic claim that hypothesis formation and confirmation is one of the key tasks of utterance comprehension.

Besides ensuring comprehension, both communicative devices select the speaker of the previous utterance as next speaker. Since they refer to one detail of the previous utterance, they both open a subsequence which, in case of coproductions, get a confirmation or a correction and in case of questions, by definition, is to be responded to. Thus, the communicative function is not only that of ensuring comprehension, but also of continuing the dialogue or winning time.

\section{Conclusion}

This article has presented how coproductions and questions about prior utterances can verbalize temporal inferences. Findings are based on qualitatively and quantitavely analysed spoken German conversation. Unlike prior research, which has taken coproductions and questions regarding prior utterances as opposite practices, it can be shown that both practices are a continuum. With coproductions and questions, speakers can refer to the different temporal aspects and both practices obtain feedback. The difference consists in that different types of questions and coproductions can verbalize the strength of assumption gradually, that is within an epistemic modality scale, as in the following schema:

A: She left already.

B1: When? (wh-question specify the temporal operator by a temporal category, no by inferences)

B2: Before or after midnight? (alternative question, presents two possible temporal operators and a high level of uncertainty)

B3: Did she leave before midnight? (yes-no question offers one possible temporal operator with uncertainty) 
B4: Before midnight? (yes-no question or coproduction with question marker offers a possible temporal operator with uncertainty)

B5: Before midnight. (coproduction presents an inferred temporal operator with certainty)

Furthermore, this shows that questions don't only verbalize a lack of knowledge, but can also verbalize certain assumptions regarding previously spoken utterances. Since this study was only dedicated to temporal inferences, further studies need to validate these findings regarding inferences of other lexical sources.

\section{References}

Auer, Peter (in press): „Projektionen und ihr Nutzen - oder: Warum die gesprochene Syntax oft minimalistisch ist."

Auer, Peter. 2002. "Projection in Interaction and Projecting in Grammar." LiSt Interaction and Linguistic Structures 33, 1-38.

Barth-Weingarten, Dagmar. 2009. "Contrasting and turn transition: Prosodic projection with parallel-opposition constructions." Journal of Pragmatics 41: 2271-2294.

Blakemore, Diane. 1994. Echo questions: A pragmatic account. Lingua 94: 197-211:

Bolden, Galina B. 2003: Multiple modalities in collaborative turn sequences. Gesture 3, (2): 187-212.

Carston, Robyn. 2002. Thoughts and Utterances: The Pragmatics of Explicit Communication. Oxford: Blackwell.

Dietrich, Rainer. 1999. "Vom Inhalt zur Form. Ein semantischer Versuch zur Analyse von Modalpartikeln. In: Ausdrucksgrammatik versus Inhaltsgrammatik, Renate Freudenberg-Findeisen (eds), 129-137. München, Iudicum.

Dittmar, Norbert; Terborg, Heiner. 1991. "Modality and second language learning: A challenge for linguistic theory." In: Cross Currents in Second Language Acquisition and Linguistic Theory, Charles A. Ferguson and Tom Hübner (eds), 347-381. Amsterdam/Philadelphia: John Benjamins.

Fraser, Bruce. 1999. "What are discourse markers?" Journal of Pragmatics 31: 931-952.

Grice, H. Paul. 1989. Studies in the Way of Words. Cambridge MA: Harvard University Press.

Groenendijk, Jeroen and Stokhof, Martin. 1997. "Questions.” In: Handbook of logic and language. Johan van Benthem and Alice ter Meulen (eds), 1055-1124. Amsterdam/ Lausanne/ New York u.a: Elsevier Science.

Hayashi, Makoto. 2004. "Projection and grammar: notes on the 'action-projecting' use of the distal demonstrative are in Japanese." Journal of Pragmatics 36: 1337-1374.

Helasvuo, Marja-Liisa. 2004. "Shared syntax: the grammar of co-constructions." Journal of Pragmatics 36: 1315-1336.

Horn, Laurence. 2007. "Neo-Gricean Pragmatics: a Manichaen Manifesto." In: Pragmatics. (Palgrave Advances in Linguistics.) Noel Burton-Roberts (ed.), 158183. London Palgrave Macmillan.

Klein, Wolfgang. 2009. "How time is encoded." In: The expression of time. W. Klein \& P. Li (eds.), 39-82. Berlin: Mouton de Gruyter.

Klein, Wolfgang. 1994. Time in language. London: Routledge. 
Lerner, GeneH. 2004. „Collaborative turn sequences.” In: Conversation Analysis: Studies from the First Generation. Gene H. Lerner (ed.), 225-256. Amsterdam/Philadelphia: John Benjamins.

Levinson, S.C. (2000) Presumptive Meanings: The Theory of Generalized Conversational Implicature. Cambridge, MA: The MIT Press.

Linke, Angelika and Nussbaumer, Markus. 2000. „Konzepte des Impliziten: Präsuppositionen und Implikaturen. “ In: Text- und Gesprächslinguistik. (Handbücher zur Sprach- und Kommunikationswissenschaft (HSK) 16.1. Klaus Brinker (ed.), 435-448. Berlin/New York: de Gruyter.

Noh, Eun-Ju (1995): "Echo questions: Metapresenatition and Pragmatic Enrichment." Linguistics and Philosophy 21: 603-628.

Recanati, François. 2007. "It is Raining (Somewhere)." Linguistics and Philosophy 30 (1): 123-146.

Recanati, François. 2004. Literal meaning. Cambridge: Cambridge University Press.

Reichenbach, Hans. 1947. Elements of Symbolic Logic. New York: Free Press.

Rost-Roth, Martina. 2006. Nachfragen: Formen und Funktionen äußerungsbezogener Interrogationen, Berlin: Gruyter.

Sacks, Harvey. 1992. Lectures on conversation, With an introduction by Emanuel A. Schlegloff. Gail Jefferson (ed.) Oxford/ Cambridge, Mass.: Blackwell.

Szczepek, Beatrice. 2000. "Functional Aspects of Collaborative Productions in English Conversation.” InLiS 21. http://ling.sprachwiss.uni-konstanz.de/pages/anglistik/.

Smith, Carlota S. 2007. Tense and temporal interpretation. Science Direct. Lingua 117: 419-436

Sperber, Dan and Deirdre Wilson. 1986/96. Relevance. Communication and Cognition. Oxford: Basil Blackwell.

Stanley, Jason. 2007. Language in Context. Selected essays. Oxford: Oxford University Press.

van Berkum, J. J. A. 2008. "Understanding sentences in context: What brain waves can tell us." Current Directions in Psychological Science 17 (6): 376-380.

\section{About the Author}

Christine Paul is a PhD student at the Free University Berlin and lecturer at the Goethe Institute Berlin. She studied Romance Languages and German Linguistics at the Free University Berlin and recieved a Scholarship in order to study at the University of Lima (Peru). Her research interests lie in semantics, pragmatics, discourse analysis, and conversation analysis. 